\title{
Translation control of Enterovirus A71 gene expression
}

\author{
Ming-Chih Lai ${ }^{1,2,3}$, Han-Hsiang Chen ${ }^{2}$, Peng $\mathrm{Xu}^{4^{*+}}$ and Robert Y. L. Wang ${ }^{1,25^{* \dagger}}$ (D)
}

\begin{abstract}
Upon EV-A71 infection of a host cell, EV-A71 RNA is translated into a viral polyprotein. Although EV-A71 can use the cellular translation machinery to produce viral proteins, unlike cellular translation, which is capdependent, the viral RNA genome of EV-A71 does not contain a 5' cap and the translation of EV-A71 protein is cap-independent, which is mediated by the internal ribosomal entry site (IRES) located in the 5' UTR of EVA71 mRNA. Like many other eukaryotic viruses, EV-A71 manipulates the host cell translation devices, using an elegant RNA-centric strategy in infected cells. During viral translation, viral RNA plays an important role in controlling the stage of protein synthesis. In addition, due to the cellular defense mechanism, viral replication is limited by down-regulating translation. EV-A71 also utilizes protein factors in the host to overcome antiviral responses or even use them to promote viral translation rather than host cell translation. In this review, we provide an introduction to the known strategies for EV-A71 to exploit cellular translation mechanisms.
\end{abstract}

Keywords: Enterovirus A71, Translational control, Host factors, Gene expression

\section{Background}

Enterovirus A71 (EV-A71) infection is one of the major causes of hand-foot-and-mouth disease (HFMD) mainly in young children and infants worldwide $[1,2]$. In 1969, EV-A71 was first isolated from a child with encephalitis in California, USA [1]. Since then, several outbreaks have been reported worldwide. In 1998, EV-A71 infection caused HFMD and herpangina in more than one hundred thousand people in Taiwan, which led to 78 fatalities because of serious neurological complications [2]. EV-A71 epidemic has therefore become a serious threat to public health, especially in the Asia-Pacific region. EV-A71 transmits mainly via oral-fecal aerosol and droplet routes [3]. To date, human is the only known host found for EV-A71. Generally, EV-A71 infection is asymptomatic to a mild form of disease and can be overcome by our immune system. The typical clinical symptoms of HFMD caused by EV-A71 include papulovesicular

\footnotetext{
* Correspondence: 83802360@qq.com; yuwang@gap.cgu.edu.tw

${ }^{\dagger}$ Peng Xu and Robert Y. L. Wang contributed equally to this work.

${ }^{4}$ Xiangyang No.1 People's Hospital, Hubei University of Medicine, Shiyan,

Hubei Province, China

'Department of Biomedical Sciences, College of Medicine, Chang Gung

University, Taoyuan 33302, Taiwan

Full list of author information is available at the end of the article
}

which is the rash found on hands and legs and herpangina which are the ulcers on lips and tongue [3]. Occasionally, EV-A71 can invade into central nervous system (CNS) to cause acute neurological complications, such as aseptic meningitis and encephalitis, and even lead to death. Although EV-A71 is a neurotropic virus, the chance is not high for it to invade into CNS due to the existence of human physical barriers, such as blood brain barrier (BBB). Viruses transmit into $\mathrm{CNS}$ via $\mathrm{BBB}$ route, which is mediated by immune cells or via retrograde axonal transport. Retrograde axonal transport has been reported to be the major route for EV-A71 to invade into CNS in mice. However, as EV-A71 can infect immune cells, BBB route is also possible to be employed by EV-A71 to facilitate its invasion into CNS. Both EV-A71 replication in CNS and the subsequent cytokine storm caused by the over stimulation of the immune system might contribute to the acute neurological complications. Overall, in addition to HFMD, EV-A71 can also cause diverse neurological complications, such as aseptic meningitis, poliomyelitis-like acute flaccid paralysis, brainstem encephalitis, or even death [3]. In the past, there have been quite a few literatures on molecular biology research on EV-A71, from viral 
entry, viral replication, viral packaging, and the relationship between viruses and hosts [4]. In this review, we focus on the advances in translational control of EV-A71 gene expression. A better understanding of the regulation of viral gene expression will certainly contribute to the development of vaccines and antiviral drugs.

\section{Structure and function of Enterovirus A71 viral RNA and proteins}

EV-A71 is a small non-enveloped virus composed of an icosahedral capsid and belongs to the genus of Enterovirus in the Picornaviridae family. The structure of the EV-A71 genome is a single-stranded positivesense RNA encoding a large open reading frame (ORF) flanked by a highly structured 5 '-untranslated region (UTR) and a $3^{\prime}$-UTR with a poly (A) tail (Fig. 1). The 5'-UTR of EV-A71 RNA is approximately 750 nucleotides (nt) that contains six stemloop structures (domains I-VI) [5]. The cloverleaf-like domain I is a cis-acting replication element for the synthesis of negative strand RNA as the template [6], whereas domains II-VI form an internal ribosome entry site (IRES) element that facilitates ribosome recruitment. EV-A71 RNA lacks the 5' cap structure $(\mathrm{m} 7 \mathrm{GpppN})$ and thus initiates translation of the viral RNA by a cap-independent and IRES-mediated mechanism [7]. Viral RNA encodes a large polyprotein that, through a series of proteases-mediated processing events, produces 11 viral proteins, including 4 structural proteins (VP1, VP2, VP3, and VP4) and 7 nonstructural proteins $(2 \mathrm{~A}, 2 \mathrm{~B}, 2 \mathrm{C}, 3 \mathrm{~A}, 3 \mathrm{~B}, 3 \mathrm{C}$, and $3 \mathrm{D})$. The non-structural proteins are involved in the expression and replication of viral genes. The 3'-UTR of EV-A71 RNA contains three putative stem-loop structures (X, Y, and Z) that are involved in viral replication [8]. In order to complete the life cycle of EV-A71, viral proteins are involved in translational control of viral and host mRNAs.

\section{Inhibition of host cell translation after EV-A71 infection}

EV-A71 causes rapid inhibition of host cell capdependent translation during viral infection, and this preferably allows for cap-independent translation of its own genomic RNA by the IRES element [9]. EV-A71encoded proteases $2 \mathrm{~A}^{\text {pro }}$ and $3 \mathrm{C}^{\text {pro }}$ are important for viral polyprotein processing. Viral proteases not only cleave viral polypeptides, but also inhibit cap-dependent translation primarily by cleavage of translation initiation factors (eIFs) in host cells. 2A $\mathrm{A}^{\text {pro }}$ cleaves eukaryotic initiation factor $4 \mathrm{G}$ (eIF4G) $[10-14], 3 C^{\text {pro }}$ cleaves eukaryotic initiation factor 4A (eIF4A) [15] and eukaryotic initiation factor 5B (eIF5B) [16], resulting in the shut off of host cell translation. Cleavage of poly (A)-binding protein (PABP) by $3 \mathrm{C}^{\text {pro }}$ also helps to inhibit host cell translation [17-19]. In addition, $2 \mathrm{~A}^{\text {pro }}$ induces stress granule formation in the EV-A71-infected cells [20]. Stress granules formation is accompanied by disassembly of polysomes and translation inhibition [21]. EV-A71 infection also induces endoplasmic reticulum (ER) stress [22]. Under such a condition, the doublestranded RNA-dependent protein kinase PKR phosphorylates the regulatory $\alpha$ subunit of eukaryotic translation initiation factor 2 (eIF2 $\alpha$ ) to block translation of both cellular and viral mRNAs. After EV-A71 infection, $3 C^{\text {pro }}$ cleaves PKR to activate viral translation and replication [23]. Notably, a cleavage fragment of eIF5B, a product of viral $3 C^{\text {pro }}$, can be substituted for eIF2 to deliver MettRNAi to the $40 \mathrm{~S}$ ribosomal subunit, while eIF2 $\alpha$ is phosphorylated and inactivated by viral infection [24]. Therefore, the regulation of EV-A71 mRNA translation may be a dynamic process.

\section{Mechanism of EV-A71 viral RNA translation}

Translation of EV-A71 is mediated by a type 1 IRES element in the $5^{\prime}$-UTR of viral RNA, allowing proceed the cap-independent of viral protein synthesis in the

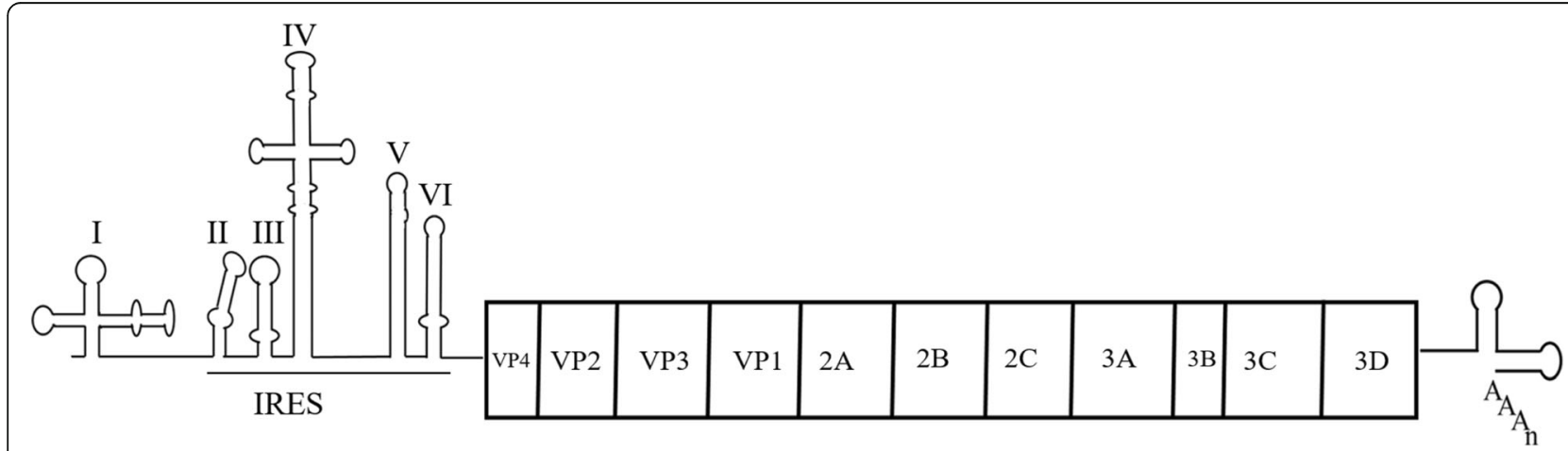

Fig. 1 The structure of the EV-A71 genome. The 5' UTR of EV-A71 contains six stem-loop RNA domains (I-VI). Domain I functions in negativestrand RNA synthesis, whereas domains II-VI form an IRES element. The ORF encodes a polyprotein, which is cleaved into 11 viral proteins by viral and/or cellular proteases 
host cells [7]. EV-A71 IRES (domains II-VI) spans approximately $450 \mathrm{nt}$ long (Fig. 2). Domain II is a short stem-loop that harbors a conserved AUAGC motif. Domains III and VI are more variable, whereas domains IV and $\mathrm{V}$ are relatively conserved. Domain IV harbors an internal C-rich loop and a GNRA ( $\mathrm{N}$ stands for any nucleotide, and R for purine) motif [25]. Domain V consists of a hairpin with an internal loop and interacts with eIF4G and eIF4A for 48S ribosomal assembly [26]. The $\mathrm{Yn}$-Xm-AUG (Yn is a pyrimidine-rich region and $\mathrm{Xm}$ is a 15- to 25-nucleotide spacer followed by an AUG codon) motif is conserved in most picornaviruses and located within domain VI of the IRES element. This motif has been proposed to be the ribosome entry site but not as a translation initiation codon [27]. The real AUG start codon is about $750 \mathrm{nt}$ downstream of the $5^{\prime}$ end. The translation of IRES for EV-A71 still requires binding of the canonical initiation factors, including eIF1, eIF1A, eIF2, eIF3, eIF4A, eIF4B, and the central domain of eIF4G [28]. The truncated eIF4G is a product of the viral $2 \mathrm{~A}^{\text {pro }}$ that specifically binds to domain $\mathrm{V}$ of EV-A71 IRES and recruits eIF4A to promote the formation of the $43 \mathrm{~S}$ pre-initiation complex [26]. In contrast, hepatitis $\mathrm{C}$ virus (HCV) IRES is the prototype of type 3 IRESs that requires only a small portion of the canonical initiation factors to form the $48 \mathrm{~S}$ initiation complex [29]. Many viral IRESs require a variety of RNA binding proteins (RBPs), termed IRES-transacting factors (ITAFs), to facilitate the recruitment of the $40 \mathrm{~S}$ ribosomal subunits [30]. To date, many ITAFs have been shown to stimulate EV-A71 IRES activity, including heterogeneous nuclear ribonucleoprotein A1 (hnRNP A1) [31-33], polypyrimidine tract-binding protein 1 (PTB1) [34-37], poly (rC)binding proteins 1 and 2 (PCBP1/2) [38-40], the 68-kDa Src-associated protein in mitosis (Sam68) [41], the DEAD-box RNA helicase DDX3 [42], HuR and Ago2
[43], and far-upstream element-binding protein 1 (FBP1) [44]. Although FBP1 was identified as an ITAF [44], FBP2 was shown to inhibit EV-A71 IRES activity in the EV-A71-infected cells [45]. AU-rich element-binding protein 1 (AUF1) also negatively regulates enterovirus infections [46, 47]. AUF1 and hnRNP A1 compete for the same IRES domain to downregulate or upregulate viral translation. Like many other viruses, EV-A71 translation is delicately regulated by host cell proteins.

\section{Cellular proteins involved in the regulation of EV- A71 mRNA translation}

In EV-A71-infected cells, cap-dependent translation is shut off and IRES-mediated translation is activated by host cell proteins (Table 1). IRES elements can recruit the $40 \mathrm{~S}$ ribosomal subunit directly or by using eIFs and auxiliary RBPs, which are identified as ITAFs. Most ITAFs are nuclear proteins that are redistributed to the cytoplasm during viral infection and cellular stress. After EV-A71 infection, many cellular proteins are attracted to the IRES element to facilitate viral mRNA translation (Fig. 3). Misshapen NCK-related kinase (MINK) is involved in many important cellular processes, such as cell growth, cytoskeletal rearrangement, and movement. At early stage of EV-A71 infection, EV-A71 induces phosphorylation of MINK, and the downstream of p38 MAPK, which then stimulates the relocalization of hnRNP A1 into the cytoplasm where it binds to the viral IRES and recruits ribosomes to promote IRES-mediated translation of viral mRNAs [55]. The hnRNP A1 binding sites on the EV-A71 IRES were identified in domains II and VI [32]. In addition, the function of hnRNP A1 in the enhancement of EV-A71 IRES-mediated translation can be substituted by hnRNP A2 (Fig. 3). When hnRNP A2 is inhibited, EV-A71 translation is reduced. It is found that hnRNP A2 interacts with EV-A71 IRES

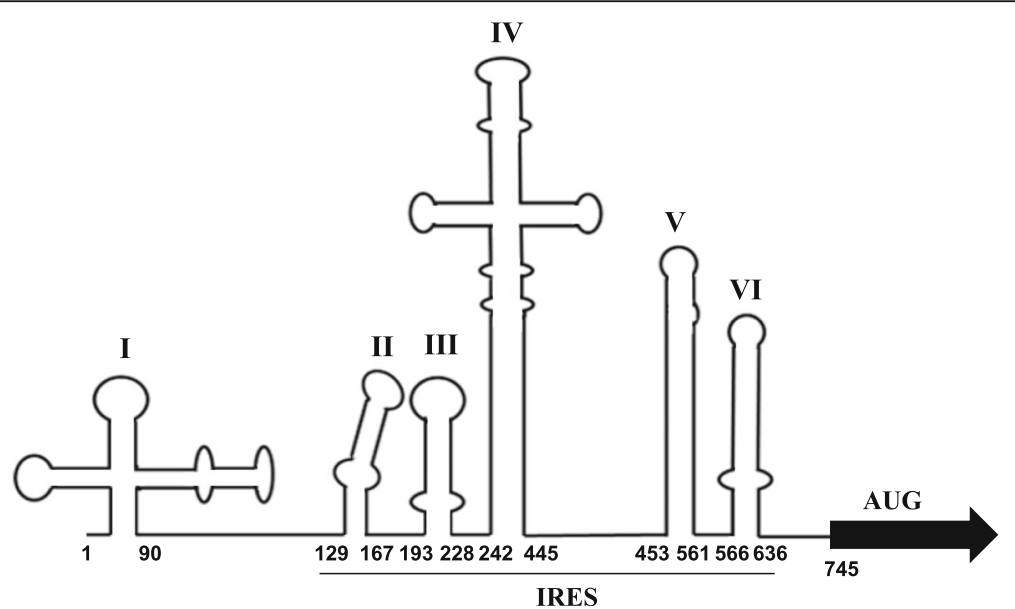

Fig. 2 Diagram of the EV-A71 5' UTR. Line drawing shows the predicted secondary structure motifs. The first and last nucleotides in each stemloop domains are numbered. Domain II to VI constitute the IRES element 
Table 1 Cellular proteins involved in the regulation of enterovirus A71 mRNA translation

\begin{tabular}{|c|c|c|}
\hline Host factors & The effects of host proteins on EV-A71 translation & Refs \\
\hline hnRNP A1/A2 & $\begin{array}{l}\text { hnRNP A1 promotes IRES-mediated translation after EV-A71 infection and its function in translation can be } \\
\text { replaced by hnRNP A2. }\end{array}$ & [31-33] \\
\hline PTB1 & $\begin{array}{l}\text { Nuclear PTB1 is transferred to the cytoplasm and interacts with EV-A71 IRES domain VI to promote viral } \\
\text { mRNA translation. }\end{array}$ & [34-37] \\
\hline PCBP1/2 & PCBP1/2 also function as ITAFs by interaction with domain IV of type 1 IRES to promote viral translation. & [48-50] \\
\hline Sam68 & Sam68 binds specifically to EV-A71 IRES domains IV and V and acts as an ITAF to upregulate viral translation. & [41] \\
\hline DDX3 & $\begin{array}{l}\text { DDX3 may indirectly binds to the domain VI of EV-A71 IRES and then unwind the secondary structure to } \\
\text { facilitate ribosome entry. }\end{array}$ & [42] \\
\hline HuR & HuR binds to the domain II of EV-A71 IRES by viral small RNA and promotes viral IRES-mediated translation. & [43] \\
\hline Ago2 & Ago2 binds to the domain II of EV-A71 IRES by viral small RNA and promotes viral IRES-mediated translation. & [43] \\
\hline FBP1 & $\begin{array}{l}\text { FBP1 binds to the EV-A71 } 5^{\prime} \text { UTR linker region to promote IRES-mediated translation and virus production. } \\
\text { FBP1 activates viral IRES activity by competing with FBP2. }\end{array}$ & [44] \\
\hline FBP2 & FBP2 binds to the IRES of EV-A71 and acts as a negative regulator of viral IRES-mediated translation. & [45] \\
\hline AUF1 & AUF1 binds to the domain II of EV-A71 IRES by viral small RNA and represses viral IRES-mediated translation. & {$[46,47]$} \\
\hline SRp20 & SRp20 interacts with PCBP2 and functions to promote type 1 IRES-mediated translation. & {$[51,52]$} \\
\hline Hsp27 & $\begin{array}{l}\text { Hsp27 activates viral protease } 2 \mathrm{~A}^{\text {pro }} \text { to cleave host elF4G protein, and thus inhibits host cap-dependent } \\
\text { translation and enhances viral IRES-mediated translation. }\end{array}$ & [53] \\
\hline Hsc 70 & $\begin{array}{l}\text { Hsc } 70 \text { enhances viral } 2 A^{\text {pro }} \text { activity to cleave host elF4G protein, and thus inhibits host cap-dependent } \\
\text { translation and enhances viral IRES-mediated translation. }\end{array}$ & [54] \\
\hline MINK & $\begin{array}{l}\text { EV-A71 infection induces the phosphorylation of MINK and then stimulates the transfer of hnRNP A1 } \\
\text { into the cytoplasm where it binds to the viral IRES and promotes viral IRES-mediated translation. }\end{array}$ & [55] \\
\hline
\end{tabular}

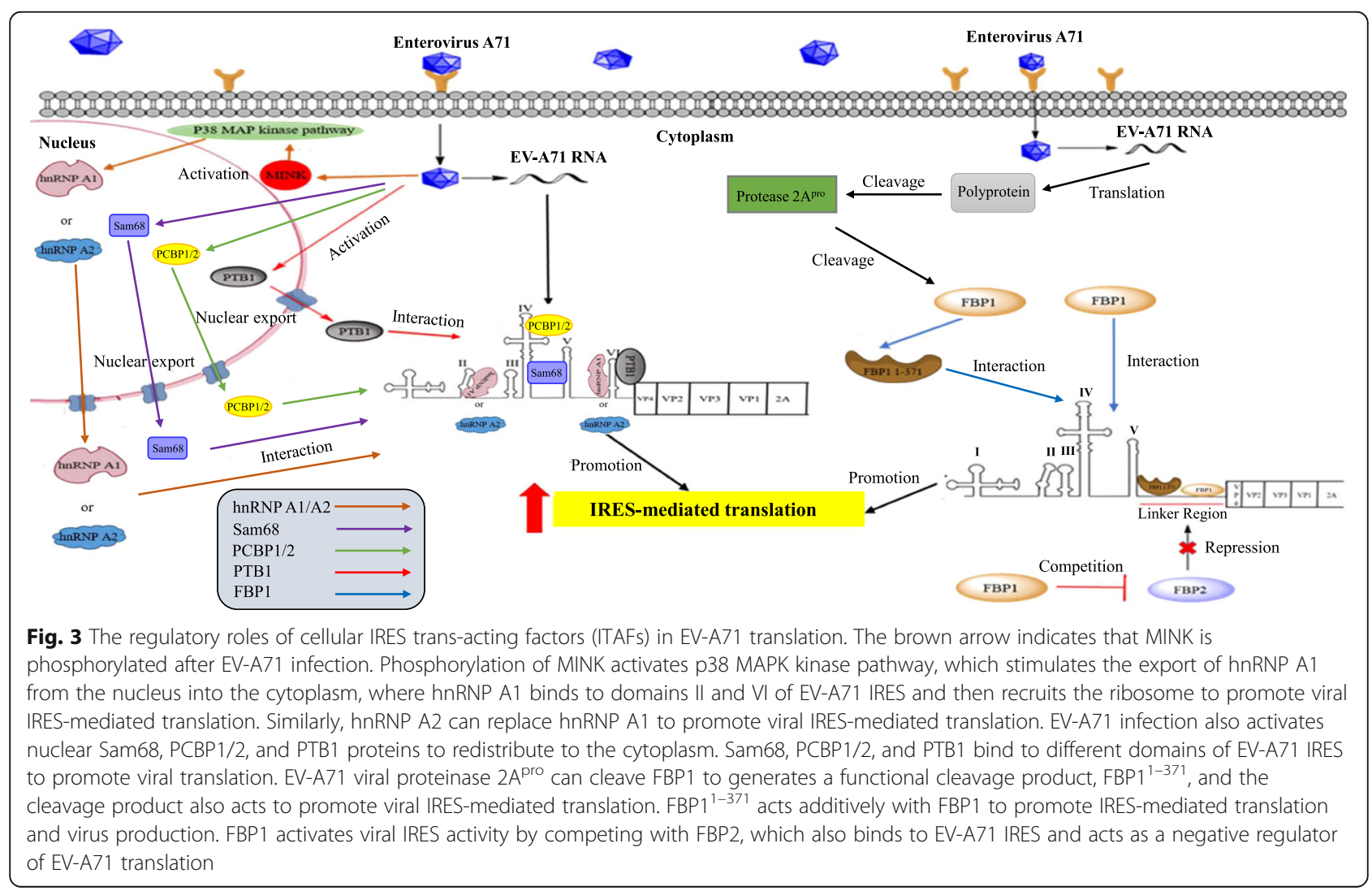


structure. Both hnRNP A1 and hnRNP A2 can synergistically promote the IRES-mediated translation of EVA71. PTB1, also known as hnRNP I, was reported as an ITAF soon after the discovery of viral IRES [56]. PTB1 binds to pyrimidine-rich RNA sequences and has multiple functions in pre-mRNA splicing, polyadenylation, and viral IRES-mediated translation. PTB1 is involved in many viral translation initiations such as poliovirus, EMCV, HRV14, and FMDV. After EV-A71 infection, nuclear PTB1 is redistributed to the cytoplasm and interacts with domain VI of EV-A71 IRES via its RNA recognition motifs 1 and 2 (RRM1 and 2), thus increases the activity of EV-A71 IRES-mediated translation [34, 35] (Fig. 3). Sam68 is a $68 \mathrm{kDa}$ nuclear protein associated with Src in mitosis, a member of the STAR family of proteins involved in message transmission and RNA activation. The cellular factor Sam68 binds specifically to EV-A71 IRES domains IV and V and acts as an ITAF to up-regulate viral translation [41] (Fig. 3). PCBP1/2 also function as ITAFs by interaction with domain IV of type 1 IRES to promote viral translation [48-50]. When PCBP1/2 is inhibited, IRES-mediated translation is reduced [57]. PCBP1/2 contain three hnRNP $\mathrm{K}$ homology $(\mathrm{KH})$ domains which are involved in RNA binding [58]. PCBP2 binding to domain IV of EV-A71 IRES is also required for $48 \mathrm{~S}$ complex formation and viral translation [28] (Fig. 3). The Ser-Arg-rich (SR) proteins is required for constitutive and alternative splicing. A subset of SR proteins shuttles continuously between the nucleus and the cytoplasm and play a role in mRNA translation [59]. It has been reported that SRp20 interacts with PCBP2 and functions to promote type 1 IRESmediated translation [51, 52]. Thus, SRp20 may also function in facilitating EV-A71 translation. EV-A71 viral proteinase $2 \mathrm{~A}^{\text {pro }}$ can cleave $\mathrm{FBP} 1$ to generates a functional cleavage product, $\mathrm{FBP} 1^{1-371}$, and the cleavage product also acts to promote viral IRES-mediated translation [60] (Fig. 3). FBP1 binds to the EV-A71 5' UTR linker region at nt. $686-714$, while $\mathrm{FBP} 1^{1-371}$ similarly binds to the $5^{\prime}$ UTR linker region at a different site located at nt. 656-674, and acts additively with FBP1 to promote IRES-mediated translation and virus production. Studies have already confirmed that most ITAF can enhance viral IRES activity; however, several ITAFs can

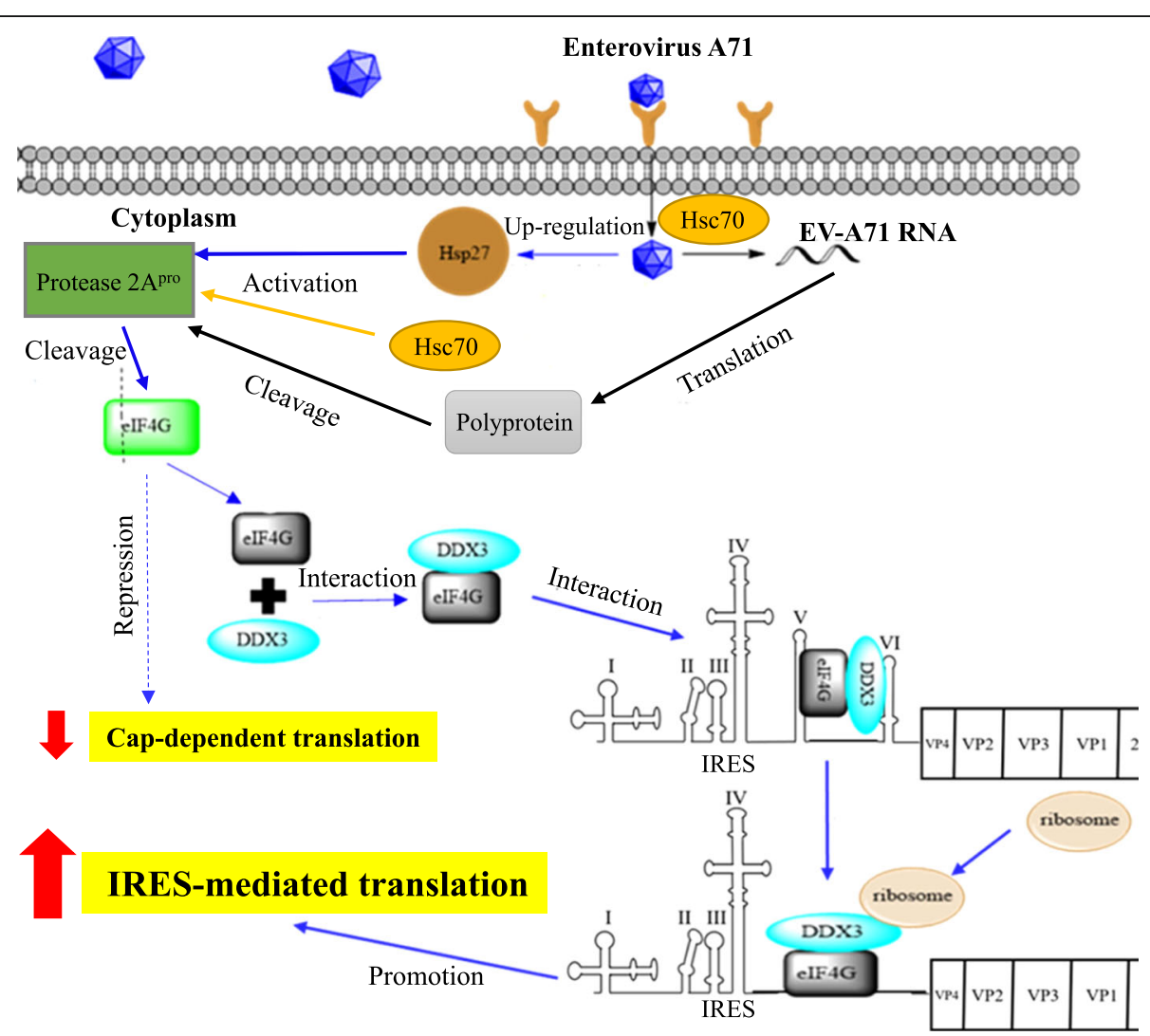

Fig. 4 The regulatory roles of Hsp27, Hsc70, and DDX3 in EV-A71 translation. EV-A71 infection upregulates Hsp27 protein expression. Hsp27 can activate EV-A71 2A $\mathrm{A}^{\text {pro }}$ to cleave elF4G, leading to inhibition of cap-dependent translation. Hsc70 also activates EV-A71 $2 \mathrm{~A}^{\text {pro }}$ protein to cleave elF4G and thus represses cap-dependent translation of host mRNAs. DDX3 interacts with the C-terminal cleavage fragment of elF4G and binds to the domain VI of EV-A71 IRES. DDX3 may unwind RNA secondary structures to facilitate ribosome entry and thus enhance viral IRES-mediated translation 
repress IRES-mediated translation. FBP1 and FBP2 are two new ITAFs of EV-A71. Upon EV-A71 infection, FBP1 activates viral IRES activity by competing with FBP2, which also binds to the IRES of EV-A71 and acts as a negative regulator of EV-A71 translation [44, 45] (Fig. 3).

It has been well known that the proteolytic activity of viral $2 \mathrm{~A}^{\text {pro }}$ is important for inhibiting host capdependent translation and enhancing viral IRESmediated translation [61]. Viral $2 \mathrm{~A}^{\text {pro }}$ cleaves host eIF4G protein to generate two fragments. The N-terminal cleavage fragment of eIF4G contains the binding site for eIF4E, leading to inhibition of cap-dependent translation. The C-terminal cleavage fragment of eIF4G is sufficient to promote IRES-mediated translation (Fig. 4). Hsp27 is a member of the large heat shock protein (HSP) families that are ubiquitously expressed in many organisms in both prokaryotes and eukaryotes. The function of Hsp27 is to prevent the protein aggregation during the heat shock and protect cells from cellular stress such as pathogen invasion. EV-A71 infection upregulates the protein expression of $\mathrm{Hsp} 27$, which can activate viral $2 \mathrm{~A}^{\text {pro }}$ to promote viral IRES-mediated translation [53] (Fig. 4). Hsc70 is a widely expressed cellular protein located in both the nucleus and cytoplasm [62]. The important role of $\mathrm{Hsc70}$ is to regulate clathrinmediated endocytosis. Hsc70 regulates the entry of EVA71 and Japanese encephalitis virus (JEV) into host cells by endocytosis [63, 64] (Fig. 4). After EV-A71 infection, Hsc70 also enhances viral $2 \mathrm{~A}^{\text {pro }}$ activity to promote viral IRES activity [54]. DDX3 is a member of the DEAD-box RNA helicase family. DDX3 is known to be involved in the regulation of mRNA translation and cell cycle [65, 66]. In addition, DDX3 is also implicated in controlling viral infections, such as JEV, HBV, HCV, and human immunodeficiency virus type 1 (HIV-1). It was recently reported that DDX3 is required for stimulation of EV-A71 IRES activity [42]. Through interaction with the Cterminal cleavage fragment of eIF4G, DDX3 may be recruited to a region near domain VI of EV-A71 IRES and then unwind the secondary structure to facilitate ribosome entry [42] (Fig. 4).

MicroRNAs are small, non-protein-encoded RNAs that interfere with the normal function of endogenous mRNA. By post-transcriptional regulation of gene expression, miRNAs are also affected by viruses to promote viral infections; such as certain cellular miRNAs that regulate HCV and HIV-1 replication. EV-A71 infection also activates the transcription factor EGR1 to induce the expression of miR-141, which targets the capbinding protein eIF4E to shut off host protein synthesis [67] (Fig. 5). Up-regulation of miR-141 may facilitate the conversion from cap-dependent to cap-independent translation, thereby promoting viral propagation. Viral infection can induce the production of virus-derived small RNAs (vsRNAs). After EV-A71 infection, Dicer

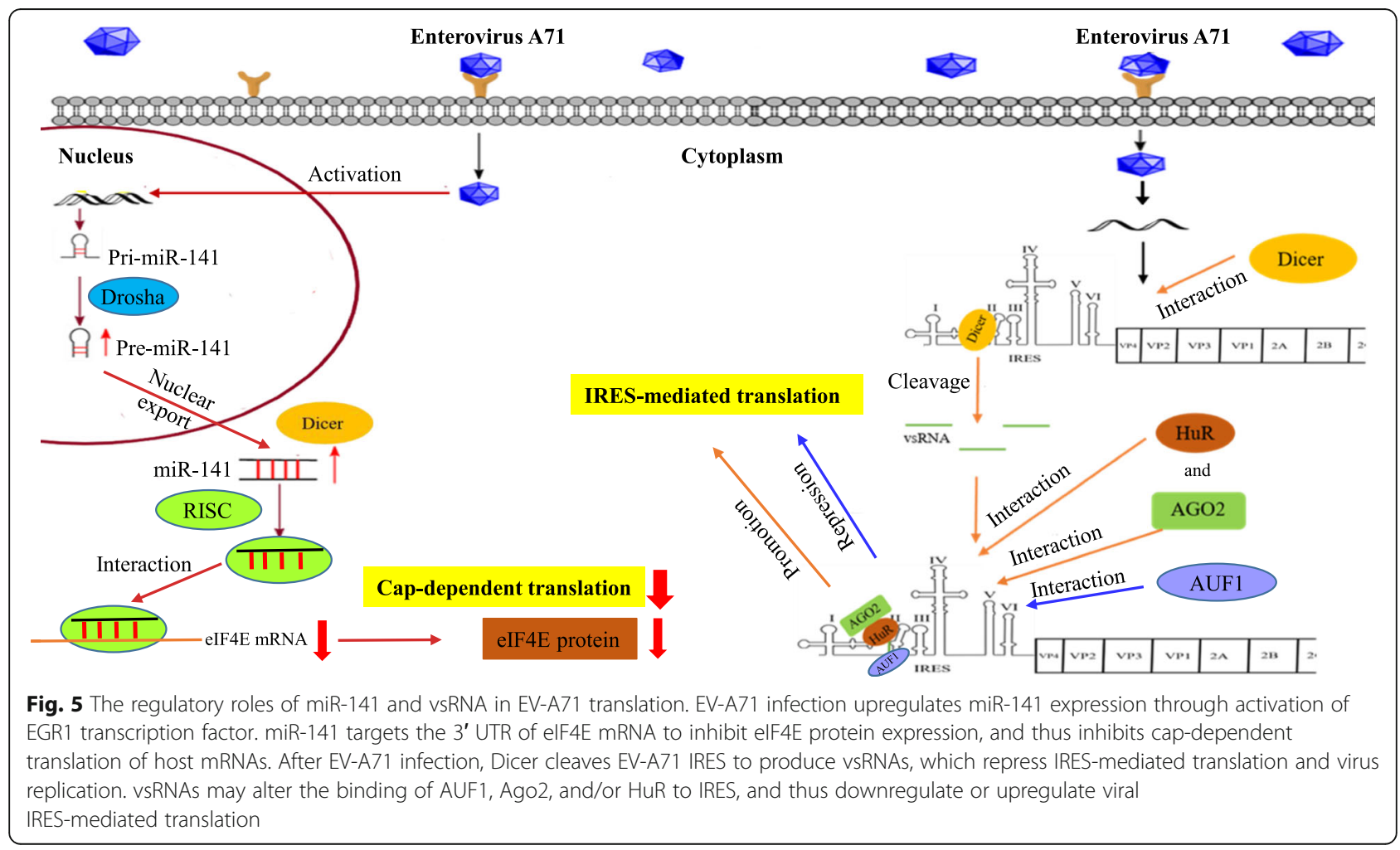


cleaves viral RNA to produce at least four vsRNAs [68] (Fig. 5). One of these vsRNAs, vsRNA1, derived from the domain II of EV-A71 IRES, reduces IRES activity and virus replication [43]. The mechanism of vsRNA1 action remains unclear.AU-rich element binding factor 1 (AUF1), an mRNA decay factor, interacts with the EV71 IRES to negatively regulate IRES-mediated translation [69]. HuR is a member of the ELAVL protein family and its well-known function is to stabilize mRNA in order to regulate gene expression. HuR and the RISC subunit Argonaute 2 (Ago2) were identified as two ITAFs that bind to the domain II of EV-A71 IRES to promote IRES activity and virus replication [43]. AUF1, HuR and Ago2 associate with the same IRES domain (domain II) in EVA71 [43]. It is speculated that vsRNA1 might alter the binding of AUF1, Ago2, and/or HuR to regulate viral IRES-mediated translation (Fig. 5).

\section{Conclusions}

Despite the progress in our understanding of the EVA71 translation in the last 20 years, many questions remain on such basic aspects as how the viral genome is translated efficiently. Also, the interactions between EVA71 and host cellular factors on the translational machinery remain either controversial or poorly known. As we have known that EV-A71 manipulates the host cell translation devices, using an elegant RNA-centric strategy in infected cells, therefore, viral RNA plays an important role in controlling the stage of protein synthesis. In this review, we also describe how EV-A71 utilizes protein factors and small RNAs in the host to promote viral IRES-mediated translation rather than host cell cap-dependent translation. Such aspects could become critical in our understanding of EV-A71 viral pathogenesis. Hopefully, more basic research in the future will give us a clearer understanding of the translation of EVA71 and take the opportunity to find more ways to fight against the virus.

\section{Acknowledgements}

Not applicable.

\section{Authors' contributions}

$\mathrm{M}-\mathrm{CL}$ and $\mathrm{H}-\mathrm{HC}$ wrote the first version of manuscript. H-HC and R-YLW designed and illustrated table and Figures. PX and R-YLW prepared the final version of manuscript. All authors read and approved the final manuscript.

\section{Funding}

This research was supported in part by grants from the Ministry of Science and Technology, Taiwan (MOST107-2320-B-182-029、MOST 108-2320-B-182008) and Chang Gung Memorial Hospital Research Fund (CMRPD1H0321、CMRPD1H0052、CMRPD1F0281-2、CMRPD1E04113、NMRPD1H0691). This work was also financially supported by the Research Center for Emerging Viral Infections from The Featured Areas Research Center Program within the framework of the Higher Education Sprout Project by the Ministry of Education (MOE) in Taiwan and the Ministry of Science and Technology, Taiwan (MOST 107-3017-F-182-001).
Availability of data and materials

Not applicable.

Ethics approval and consent to participate

Not applicable.

Consent for publication

Not applicable.

\section{Competing interests}

The authors declare that they have no competing interests.

\section{Author details}

'Department of Biomedical Sciences, College of Medicine, Chang Gung University, Taoyuan 33302, Taiwan. ${ }^{2}$ Graduate Institute of Biomedical Sciences, College of Medicine, Chang Gung University, Taoyuan 33302,

Taiwan. ${ }^{3}$ Department of Colorectal Surgery, Chang Gung Memorial Hospital at Linkou, Taoyuan 33305, Taiwan. ${ }^{4}$ Xiangyang No.1 People's Hospital, Hubei University of Medicine, Shiyan, Hubei Province, China. ${ }^{5}$ Division of Pediatric Infectious Disease, Department of Pediatrics, Chang Gung Memorial Hospital at Linkou, Taoyuan 33305, Taiwan.

Received: 5 July 2019 Accepted: 19 December 2019

Published online: 08 January 2020

\section{References}

1. Schmidt NJ, Lennette $\mathrm{EH}, \mathrm{Ho} H \mathrm{H}$. An apparently new enterovirus isolated from patients with disease of the central nervous system. J Infect Dis. 1974; 129(3):304-9.

2. Ho M, Chen ER, Hsu KH, Twu SJ, Chen KT, Tsai SF, et al. An epidemic of enterovirus 71 infection in Taiwan. Taiwan Enterovirus epidemic working group. N Engl J Med. 1999:341(13):929-35.

3. Ooi MH, Wong SC, Lewthwaite P, Cardosa MJ, Solomon T. Clinical features, diagnosis, and management of enterovirus 71. Lancet Neurol. 2010;9(11): 1097-105.

4. Yuan J, Shen L, Wu J, Zou X, Gu J, Chen J, et al. Enterovirus A71 proteins: structure and function. Front Microbiol. 2018;9:286.

5. Lin JY, Chen TC, Weng KF, Chang SC, Chen LL, Shih SR. Viral and host proteins involved in picornavirus life cycle. J Biomed Sci. 2009;16:103.

6. Barton DJ, O'Donnell BJ, Flanegan JB. 5' cloverleaf in poliovirus RNA is a cisacting replication element required for negative-strand synthesis. EMBO J. 2001;20(6):1439-48.

7. Thompson SR, Sarnow P. Enterovirus 71 contains a type I IRES element that functions when eukaryotic initiation factor elF4G is cleaved. Virology. 2003; 315(1):259-66.

8. Kok CC, Phuektes P, Bek E, McMinn PC. Modification of the untranslated regions of human enterovirus 71 impairs growth in a cell-specific manner. J Virol. 2012;86(1):542-52.

9. Lloyd RE, Jense HG, Ehrenfeld E. Restriction of translation of capped mRNA in vitro as a model for poliovirus-induced inhibition of host cell protein synthesis: relationship to p220 cleavage. J Virol. 1987;61(8):2480-8.

10. Sommergruber W, Ahorn H, Klump H, Seipelt J, Zoephel A, Fessl F, et al. 2A proteinases of coxsackie- and rhinovirus cleave peptides derived from elF-4 gamma via a common recognition motif. Virology. 1994;198(2):741-5.

11. Gradi A, Svitkin $\mathrm{Y}$, Imataka $H$, Sonenberg N. Proteolysis of human eukaryotic translation initiation factor elF4GII, but not elF4GI, coincides with the shutoff of host protein synthesis after poliovirus infection. Proc Natl Acad Sci U S A. 1998:95(19):11089-94.

12. Lamphear BJ, Yan R, Yang F, Waters D, Liebig HD, Klump H, et al. Mapping the cleavage site in protein synthesis initiation factor elF-4 gamma of the 2A proteases from human Coxsackievirus and rhinovirus. J Biol Chem. 1993; 268(26):19200-3.

13. Haghighat A, Svitkin Y, Novoa I, Kuechler E, Skern T, Sonenberg N. The elF4G-elF4E complex is the target for direct cleavage by the rhinovirus $2 \mathrm{~A}$ proteinase. J Virol. 1996;70(12):8444-50

14. Krausslich HG, Nicklin MJ, Toyoda H, Etchison D, Wimmer E. Poliovirus proteinase $2 \mathrm{~A}$ induces cleavage of eucaryotic initiation factor $4 \mathrm{~F}$ polypeptide p220. J Virol. 1987;61(9):2711-8.

15. Li W, Ross-Smith N, Proud CG, Belsham GJ. Cleavage of translation initiation factor 4AI (elF4AI) but not elF4All by foot-and-mouth disease 
virus $3 \mathrm{C}$ protease: identification of the elF4Al cleavage site. FEBS Lett. 2001;507(1):1-5.

16. de Breyne S, Bonderoff JM, Chumakov KM, Lloyd RE, Hellen CU. Cleavage of eukaryotic initiation factor elF5B by enterovirus 3C proteases. Virology. 2008; 378(1):118-22

17. Kuyumcu-Martinez NM, Joachims M, Lloyd RE. Efficient cleavage of ribosome-associated poly (A)-binding protein by enterovirus $3 \mathrm{C}$ protease. $J$ Virol. 2002;76(5):2062-74

18. Kuyumcu-Martinez NM, Van Eden ME, Younan P, Lloyd RE. Cleavage of poly (A)-binding protein by poliovirus 3 C protease inhibits host cell translation: a novel mechanism for host translation shutoff. Mol Cell Biol. 2004;24(4):1779-90.

19. Joachims M, Van Breugel PC, Lloyd RE. Cleavage of poly (A)-binding protein by enterovirus proteases concurrent with inhibition of translation in vitro. J Virol. 1999;73(1):718-27.

20. Wu S, Wang $Y$, Lin L, Si X, Wang T, Zhong $X$, et al. Protease $2 A$ induces stress granule formation during coxsackievirus B3 and enterovirus 71 infections. Virol J. 2014;11:192.

21. Kedersha N, Cho MR, Li W, Yacono PW, Chen S, Gilks N, et al. Dynamic shuttling of TIA-1 accompanies the recruitment of mRNA to mammalian stress granules. J Cell Biol. 2000;151(6):1257-68.

22. Jheng JR, Lau KS, Tang WF, Wu MS, Horng JT. Endoplasmic reticulum stress is induced and modulated by enterovirus 71. Cell Microbiol. 2010;12(6):796-813.

23. Chang YH, Lau KS, Kuo RL, Horng JT. dsRNA Binding Domain of PKR Is Proteolytically Released by Enterovirus A71 to Facilitate Viral Replication. Front Cell Infect Microbiol. 2017:7:284

24. White JP, Reineke LC, Lloyd RE. Poliovirus switches to an elF2-independent mode of translation during infection. J Virol. 2011;85(17):8884-93.

25. Du Z, Ulyanov NB, Yu J, Andino R, James TL. NMR structures of loop B RNAs from the stem-loop IV domain of the enterovirus internal ribosome entry site: a single $C$ to $U$ substitution drastically changes the shape and flexibility of RNA. Biochemistry. 2004;43(19):5757-71

26. de Breyne S, Yu Y, Unbehaun A, Pestova TV, Hellen CU. Direct functional interaction of initiation factor elF4G with type 1 internal ribosomal entry sites. Proc Natl Acad Sci U S A. 2009;106(23):9197-202.

27. Nicholson R, Pelletier J, Le SY, Sonenberg N. Structural and functional analysis of the ribosome landing pad of poliovirus type 2: in vivo translation studies. J Virol. 1991;65(11):5886-94.

28. Sweeney TR, Abaeva IS, Pestova TV, Hellen CU. The mechanism of translation initiation on type 1 picornavirus IRESs. EMBO J. 2014;33(1):76-92.

29. Lukavsky PJ. Structure and function of HCV IRES domains. Virus Res. 2009; 139(2):166-71.

30. Holcik M, Sonenberg N. Translational control in stress and apoptosis. Nat Rev Mol Cell Biol. 2005;6(4):318-27.

31. Levengood JD, Tolbert M, Li ML, Tolbert BS. High-affinity interaction of hnRNP A1 with conserved RNA structural elements is required for translation and replication of enterovirus 71. RNA Biol. 2013;10(7):1136-45.

32. Lin JY, Shih SR, Pan M, Li C, Lue CF, Stollar V, et al. hnRNP A1 interacts with the $5^{\prime}$ untranslated regions of enterovirus 71 and Sindbis virus RNA and is required for viral replication. J Virol. 2009;83(12):6106-14.

33. Tolbert M, Morgan CE, Pollum M, Crespo-Hernandez CE, Li ML, Brewer G, et al. HnRNP A1 alters the structure of a conserved Enterovirus IRES domain to stimulate viral translation. J Mol Biol. 2017;429(19):2841-58.

34. Hellen CU, Witherell GW, Schmid M, Shin SH, Pestova TV, Gil A, et al. A cytoplasmic 57-kDa protein that is required for translation of picornavirus RNA by internal ribosomal entry is identical to the nuclear pyrimidine tractbinding protein. Proc Natl Acad Sci U S A. 1993;90(16):7642-6.

35. Xi J, Ye F, Wang G, Han W, Wei Z, Yin B, et al. Polypyrimidine tract-binding protein regulates Enterovirus 71 translation through interaction with the internal ribosomal entry site. Virol Sin. 2019;34(1):66-77.

36. Kafasla P, Morgner N, Robinson CV, Jackson RJ. Polypyrimidine tract-binding protein stimulates the poliovirus IRES by modulating eIF4G binding. EMBO J. 2010;29(21):3710-22

37. Kafasla P, Lin H, Curry $S$, Jackson RJ. Activation of picornaviral IRESs by PTB shows differential dependence on each PTB RNA-binding domain. RNA. 2011;17(6):1120-31.

38. Sean P, Nguyen JH, Semler BL. Altered interactions between stem-loop IV within the $5^{\prime}$ noncoding region of coxsackievirus RNA and poly ( $\mathrm{rC}$ ) binding protein 2: effects on IRES-mediated translation and viral infectivity. Virology. 2009;389(1-2):45-58.

39. Choi K, Kim JH, Li X, Paek KY, Ha SH, Ryu SH, et al. Identification of cellular proteins enhancing activities of internal ribosomal entry sites by competition with oligodeoxynucleotides. Nucleic Acids Res. 2004;32(4): 1308-17.

40. Luo Z, Dong X, Li Y, Zhang Q, Kim C, Song Y, et al. PolyC-binding protein 1 interacts with $5^{\prime}$-untranslated region of enterovirus 71 RNA in membraneassociated complex to facilitate viral replication. PLoS One. 2014;9(1):e87491.

41. Zhang $H$, Song L, Cong H, Tien P. Nuclear protein Sam68 interacts with the Enterovirus 71 internal ribosome entry site and positively regulates viral protein translation. J Virol. 2015;89(19):10031-43.

42. Su YS, Tsai AH, Ho YF, Huang SY, Liu YC, Hwang LH. Stimulation of the internal ribosome entry site (IRES)-dependent translation of Enterovirus 71 by DDX3X RNA helicase and viral $2 \mathrm{~A}$ and $3 \mathrm{C}$ proteases. Front Microbiol. 2018:9:1324.

43. Lin JY, Brewer G, Li ML. HuR and Ago2 bind the internal ribosome entry site of Enterovirus 71 and promote virus translation and replication. PLoS One. 2015;10(10):e0140291.

44. Huang PN, Lin JY, Locker N, Kung YA, Hung CT, Lin JY, et al. Far upstream element binding protein 1 binds the internal ribosomal entry site of enterovirus 71 and enhances viral translation and viral growth. Nucleic Acids Res. 2011;39(22):9633-48.

45. Lin JY, Li ML, Shih SR. Far upstream element binding protein 2 interacts with enterovirus 71 internal ribosomal entry site and negatively regulates viral translation. Nucleic Acids Res. 2009;37(1):47-59.

46. Cathcart AL, Rozovics JM, Semler BL. Cellular mRNA decay protein AUF1 negatively regulates enterovirus and human rhinovirus infections. J Virol. 2013;87(19):10423-34.

47. Ullmer W, Semler BL. Direct and Indirect Effects on Viral Translation and RNA Replication Are Required for AUF1 Restriction of Enterovirus Infections in Human Cells. MBio. 2018;9(5):e01669.

48. Holcik M, Liebhaber SA. Four highly stable eukaryotic mRNAs assemble 3' untranslated region RNA-protein complexes sharing cis and trans components. Proc Natl Acad Sci. 1997;94(6):2410-4.

49. Blyn LB, Chen R, Semler BL, Ehrenfeld E. Host cell proteins binding to domain IV of the 5' noncoding region of poliovirus RNA. J Virol. 1995;69(7): $4381-9$.

50. Blyn LB, Swiderek KM, Richards O, Stahl DC, Semler BL, Ehrenfeld E. Poly (rC) binding protein 2 binds to stem-loop IV of the poliovirus RNA 5 ' noncoding region: identification by automated liquid chromatography-tandem mass spectrometry. Proc Natl Acad Sci U S A. 1996;93(20):11115-20.

51. Bedard KM, Daijogo S, Semler BL. A nucleo-cytoplasmic SR protein functions in viral IRES-mediated translation initiation. EMBO J. 2007;26(2):459-67.

52. Fitzgerald KD, Semler BL. Re-localization of cellular protein SRp20 during poliovirus infection: bridging a viral IRES to the host cell translation apparatus. PLoS Pathog. 2011;7(7):e1002127.

53. Dan $X$, Wan Q, Yi L, Lu J, Jiao Y, Li H, et al. Hsp27 responds to and facilitates enterovirus A71 replication through enhancing viral IRES-mediated translation. J Virol. 2019;93:02322-18.

54. Dong Q, Men R, Dan X, Chen Y, Li H, Chen G, et al. Hsc70 regulates the IRES activity and serves as an antiviral target of enterovirus A71 infection. Antivir Res. 2018;150:39-46.

55. Leong SY, Ong BK, Chu JJ. The role of misshapen NCK-related kinase (MINK), a novel Ste20 family kinase, in the IRES-mediated protein translation of human enterovirus 71. PLoS Pathog. 2015;11(3):e1004686.

56. Jang SK, Wimmer E. Cap-independent translation of encephalomyocarditis virus RNA: structural elements of the internal ribosomal entry site and involvement of a cellular 57-kD RNA-binding protein. Genes Dev. 1990;4(9): $1560-72$.

57. Blyn LB, Towner JS, Semler BL, Ehrenfeld E. Requirement of poly ( $\mathrm{rC}$ ) binding protein 2 for translation of poliovirus RNA. J Virol. 1997;71(8): 6243-6.

58. Leffers H, Dejgaard K, Celis JE. Characterisation of two major cellular poly ( $\mathrm{rC}$ )-binding human proteins, each containing three K-homologous (KH) domains. Eur J Biochem. 1995;230(2):447-53.

59. Sanford JR, Gray NK, Beckmann K, Cáceres JF. A novel role for shuttling SR proteins in mRNA translation. Genes Dev. 2004;18(7):755-68.

60. Hung CT, Kung YA, Li ML, Brewer G, Lee KM, Liu ST, et al. Additive promotion of viral internal ribosome entry site-mediated translation by far upstream element-binding protein 1 and an Enterovirus 71-induced cleavage product. PLoS Pathog. 2016;12(10):e1005959.

61. Sanz MA, Welnowska E, Redondo N, Carrasco L. Translation driven by picornavirus IRES is hampered from Sindbis virus replicons: rescue by poliovirus 2A protease. J Mol Biol. 2010;402(1):101-17. 
62. Stricher F, Macri C, Ruff M, Muller S. HSPA8/HSC70 chaperone protein: structure, function, and chemical targeting. Autophagy. 2013;9(12):1937-54.

63. Böcking T, Aguet F, Harrison SC, Kirchhausen T. Single-molecule analysis of a molecular disassemblase reveals the mechanism of Hsc70-driven clathrin uncoating. Nat Struct Mol Biol. 2011;18(3):295.

64. Chuang $\mathrm{C}-\mathrm{K}$, Yang T-H, Chen T-H, Yang C-F, Chen W-J. Heat shock cognate protein 70 isoform $\mathrm{D}$ is required for clathrin-dependent endocytosis of Japanese encephalitis virus in C6/36 cells. J Gen Virol. 2015;96(4):793-803.

65. Lai MC, Chang WC, Shieh SY, Tarn WY. DDX3 regulates cell growth through translational control of cyclin E1. Mol Cell Biol. 2010;30(22):5444-53.

66. Lai MC, Lee YH, Tarn WY. The DEAD-box RNA helicase DDX3 associates with export messenger ribonucleoproteins as well as tip-associated protein and participates in translational control. Mol Biol Cell. 2008;19(9):3847-58.

67. Ho B-C, Yu S-L, Chen JJ, Chang S-Y, Yan B-S, Hong Q-S, et al. Enterovirusinduced miR-141 contributes to shutoff of host protein translation by targeting the translation initiation factor elF4E. Cell Host Microbe. 2011;9(1): 58-69.

68. Weng K-F, Hung C-T, Hsieh P-T, Li M-L, Chen G-W, Kung Y-A, et al. A cytoplasmic RNA virus generates functional viral small RNAs and regulates viral IRES activity in mammalian cells. Nucleic Acids Res. 2014:42(20):12789805.

69. Lin JY, Li ML, Brewer G. mRNA decay factor AUF1 binds the internal ribosomal entry site of enterovirus 71 and inhibits virus replication. PLoS One. 2014;9(7):e103827.

\section{Publisher's Note}

Springer Nature remains neutral with regard to jurisdictional claims in published maps and institutional affiliations.

Ready to submit your research? Choose BMC and benefit from:

- fast, convenient online submission

- thorough peer review by experienced researchers in your field

- rapid publication on acceptance

- support for research data, including large and complex data types

- gold Open Access which fosters wider collaboration and increased citations

- maximum visibility for your research: over $100 \mathrm{M}$ website views per year

At $\mathrm{BMC}$, research is always in progress.

Learn more biomedcentral.com/submissions 